\title{
AKADEMİSYENLERDE CAM TAVAN SENDROMUNUN GÜÇ MESAFESİ İLE İLIŞKİSİ
}

\author{
THE RELATIONSHIP BETWEEN GLASS CEILING SYNDROME AND POWER \\ DISTANCE: A RESEARCH ON ACADEMICS
}

\author{
Esin $\mathrm{CAN}^{* *}$ \\ Sanem KAPTANOĞLU ${ }^{* * *}$ \\ Lazgeen Mohammed HALO ${ }^{* * * *}$
}

\section{Öz}

Trendlerdeki değişimle "she-conomy” (kadın ekonomisi) kavramı, dünyada giderek daha popüler hale gelse dahi tepe yönetim pozisyonlarında yer alan kadın çalışan sayısının azlığı hala dikkat çekmektedir. Bu çalışmanın amacı kadınların kariyerlerinde yükselirken karşılaştıkları cam tavan engelleri ile kültür boyutlarından biri olan güç mesafesi arasındaki ilişkiyi ortaya koymaktır. Ayrıca çalışma kapsamında, cinsiyete göre çalışanların cam tavan engellerine yönelik algıları ile güç mesafesi algıları arasında farklılık olup olmadığı da belirlenecektir. Çalışmanın evreni olarak Arap yarımadasında yer alan iki üniversite seçilmiştir. Bu üniversitelerin seçilme nedeni; süregelen savaş durumu, bölgenin politik yapısı ve toplumsal koşullar sebebi ile bu bölgede kadınların iş dünyası ve sosyal yaşamda çok daha fazla engelle mücadele etmesidir. Araştırmada veri toplama yöntemi olarak anket kullanılmıştır. Araştırma sonuçlarına bakıldığında algılanan cam tavan engelleri ve güç mesafesi arasında pozitif yönlü ve güçlü bir ilişki olduğu görülmektedir. Cam tavan engelleri ve güç mesafesine yönelik algıda ise cinsiyete dayalı bir farklılık olmadığı sonucu ortaya çıkmıştır.

Anahtar Kelimeler: Cam tavan sendromu, güç mesafesi, akademisyenler

JEL Sınıflaması: M10

* Makale Gönderim Tarihi: 29.01.2018; Kabul Tarihi: 11.05.2018

** Yıldız Teknik Üniversitesi, İktisadi ve İdari Bilimler Fakültesi, İşletme Bölümü, Prof. Dr., ORCID ID: 0000-0003-1754-4867

*** Yıldız Teknik Üniversitesi, İktisadi ve İdari Bilimler Fakültesi, İşletme Bölümü, Arş. Gör., ORCID ID: 0000-0002-6028-1428

**** University of Zakho, Department of Management Sciences, Director, ORCID ID: 0000-0003-4489-9938 


\section{Abstract}

Although labor force participation rate of women increases day by day, the number of female employees in senior management positions is still very limited. In 2017, 34\% of global corporations do not have women in top management (Women in Business: New Perspectives on Risk and Reward Report, 2017). While the proportion of women on the board of directors is limited to $12 \%$, the proportion of women board chairmen is only $4 \%$ (Deloitte, 2015). The difficulties women face in promoting to senior management positions have attracted researchers' attention. In 1986, Hymovitz and Schellhard first used the glass-ceiling metaphor to describe the constraints that prevent females to promote top management positions in corporations, state institutions, educational institutions or nonprofit organizations (Hymowitz and Schellhardt, 1986). The factors that lead to the formation of glass ceiling in enterprises can be individual (women's roles as wife and/or mother, time management problems), organizational (organizational culture, company policies and the difficulties women experience in participating in informal communication networks) (Mizrahi ve Arac1, 2010) and social (gender discrimination in society and gender stereotypes). The other concept that is examined in this study is power distance. The concept of power distance is one of the cultural dimensions described by Geert Hofstede and it is defined as "the extent to which the less powerful members of institutions and organisations within a country expect and accept that power is distributed unequally." (Hofstede, 2003). In other words, power distance shows "the level of acceptance or rejection of differences and inequalities by members in the distribution of power in the social system" (Turan, Durceylan and Şişman, 2005). The purpose of this study is to determine the relationship between the glass ceiling obstacles and the perceived level of power distance. In addition, this research investigates whether gender differences affect people's perceptions on these variables or not. The research data was collected from two universities in Iraq since women who live in this region face more barriers in the business world and the social life. In 2016, the proportion of women participating in the world labor force was $50 \%$. The labor force participation rate of females was $23 \%$ in Arab countries and only $15 \%$ in Iraq. On the other hand, the proportion of men participating in the workforce was $76 \%$ globally, 75\% in Arab countries and 70\% in Iraq (The World Bank, 2017). This difference in the labor participation rates of women and men in Iraq is basically a result of the social norms. Many girls in Iraq can't go to school at all and the biggest obstacle for girls to go to school is seen as their families. The refusal of parents to send their daughters to the school and the early marriage of young girls affect the labor force participation rate of females negatively. Interestingly, there is a positive relationship between the education levels of women in the country and the unemployment rates. The unemployment rate among women with undergraduate degrees has climbed to 68\% (Inter-Agency Information and Analysis Unit (IAU), 2012). It can be concluded that jobs are deemed as appropriate for women in the country do not require a bachelor's degree. In this study, a total of 536 questionnaires were distributed during the data collection process. 341 surveys were sent to University 1, 300 of them were answered and 297 of them were considered valid. 195 questionnaires were sent to University 2, 129 of them were answered and all of the answered questionnaires were considered valid. Total participation rate was $80 \%$. Of the 426 academics who participated in the study, $64.32 \%$ were male and $35.68 \%$ were female. $3,66 \%$ of the participants were professors, $13,15 \%$ of them were associate professors, $17,61 \%$ of them were assistant professors, $39,20 \%$ of them were lecturers and $26,29 \%$ of them were research assistants. $21.37 \%$ of these academics had an administrative role in their universities. Hypotheses of the study were formulated as: H1: There is 
a relationship between academics' power distance perceptions and their perceptions of glass ceiling syndrome; H2: There are gender differences in glass ceiling perceptions of academics; H3: There are gender differences in academics' power distance perceptions. The Pearson correlation method was used to test $\mathrm{H} 1$ and $\mathrm{T}$-Tests were used to test $\mathrm{H} 2$ and $\mathrm{H} 3$. The results of the research revealed that there is a strong positive relationship between glass ceiling obstacles perception and the perceived level of power distance. In addition, there is no gender-based difference between academics' perceptions of glass ceiling obstacles and power distance. In other words, $\mathrm{H} 1$ was supported and $\mathrm{H} 2$ and $\mathrm{H} 3$ were not supported.

Keywords: Glass ceiling syndrome, power distance, academics

JEL Classification: M10

\section{KAVRAMSAL ÇERÇEVE}

Günümüz iş dünyasında, kadınların işgücüne katılma oranı gün geçtikçe artsa da; üst yönetim kademelerinde yer alan kadın çalışanların sayısı hala oldukça sınırlıdır. 2017 yılında dünya genelinde üst yönetim pozisyonlarının yalnızca \%25'inde kadınlar görev alırken, küresel işletmelerin \%34'ünde tepe yönetimde kadın personel bulunmamaktadır (Women in Business: New Perspectives on Risk and Reward Raporu, 2017). Yönetim kurullarında kadın oranı \%12 ile sınırlı kalırken, kadın yönetim kurulu başkanlarının oranı ise sadece \%4'tür (Deloitte, 2015).

Kadınların üst yönetim pozisyonlarına yükselme konusunda yaşadıkları zorluklar araştırmacıların da dikkatini çekmiştir. İlk defa 1986 yılında, Hymovitz ve Schellhard tarafından yazılan ve Wall Street Journal'da yayınlanan bir yazıyla devlet kurumlarında, şirketlerde ve eğitim kurumlarında veya kâr amacı gütmeyen kuruluşlarda yüksek pozisyonlara gelmeyi isteyen ve bunun için çaba sarfeden kadınların karşılaştıkları engeller cam tavan olarak tanımlanmıştır (Hymowitz ve Schellhardt, 1986).

İşletmelerde cam tavan oluşumuna neden olan unsurlar bireysel, örgütsel ve toplumsal faktörlerden kaynaklanabilmektedir. Bireysel faktörlere kadınların eş ve anne olarak üstlendikleri roller ve zaman yönetimi konusunda yaşadıkları sıkıntılar örnek gösterilebilir. İşletmedeki mevcut örgüt kültürü, şirket politikaları ve kadınların informal iletişim ağlarına katılmada yaşadıkları güçlükler ise örgütsel faktörlere örnektir (Mizrahi ve Aracı, 2010). Toplumda mevcut cinsiyet eşitsizliği ve cinsiyetlere dayalı önyargılar ise toplumsal faktörlerden bazıları olarak karşımıza çıkmaktadır.

Çalışmaya konu olan diğer kavram ise güç mesafesidir. Güç mesafesi kavramı ülkelerin ve organizasyonların kültürel yapılarını inceleyen Geert Hofstede tarafından kültür boyutlarından biri olarak ifade edilmektedir (Hofstede, Hofstede ve Minkov, 2010). Bu kavram "sosyal sistemde gücün dağılımındaki farklılık ve eşitsizliklerin üyeler tarafından kabul ya 
da reddedilme düzeyi” olarak tanımlanabilir (Turan, Durceylan ve Şişman, 2005). Güç mesafesi, bir toplumun bireylerinde ve işletmelerindeki güç dağılımının eşit olup olmadığ 1 ile ilgilidir. Güç mesafesinin, yani bireylerin sahip oldukları güç arasındaki farkların yüksek olduğu toplumlarda hiyerarşik bir yapı söz konusudur, gücü elinde tutanlar ayrıcalıklara sahiptir ve toplumsal manada bir eşitsizlik söz konusu olabilmektedir (Hofstede, 2003). Güç mesafesinin düşük olduğu toplumlarda ise fırsat eşitliğine daha çok önem verilmekte, yönetilenlerin yönetenlerle bilgi ve tecrübelerini paylaşabilmeleri ve yönetenlerin bu paylaşımları dikkate almaları daha kolay olabilmektedir.

Cam tavan kadınların iş yaşamında tepe pozisyonlara yükselmelerini engelleyen görünmez bir bariyer oluşturmaktadır. Bu bariyer, insanlar arasında cinsiyete ve hiyerarşiye dayalı farklılaşmanın etkisiyle gücü elinde bulunduranların, güce sahip olmayanları kendilerinden bir basamak aşağıda görmeleriyle daha da kuvvetlenmektedir.

$\mathrm{Bu}$ çalı̧̧mada; yukarıda gösterilen nedenlerden hareketle, akademisyenlerde cam tavan sendromu algısının güç mesafesi ile ilişkisi araştırılmıştır. Çalışmanın evreni olarak Irak’ta faaliyet gösteren iki üniversitenin akademik çalışanları belirlenmiştir. International Labour Organization (ILO) verilerine göre, 2016 yılında dünya çapında işgücüne katılan kadınların oranı \%50 iken, Arap ülkeleri genelinde bu oran \%23, Irak’ta ise yalnızca \%15’tir. İgücüne katılan erkeklerin oranı ise dünya genelinde $\% 76$ iken, Arap ülkelerinde $\% 75$ ve Irak’ta \%70 olarak gerçekleşmiştir (The World Bank, 2017). Irak’ta kadın ve erkeklerin işgücüne katılım oranları arasındaki bu fark, temelde toplumsal normların bir sonucu olarak karşımıza çıkmaktadır. Iraklı kadınların iş hayatında yeterince yer bulamamasının sebebi ülkedeki kız çocuklarının yeterince eğitim alamamasıdır. Ülke genelinde okuma yazma bilmeyen kadınların oranı erkeklerin iki katı iken, kız çocuklarının okula gitmelerinin önündeki en büyük engel ise aileleleri olarak görülmektedir. Ailelerin kız çocuklarını okula göndermeyi reddetmeleri ve genç kızların erken yaşta evlendirilmeleri, kadınların iş hayatına katılmasına engel teşkil etmektedir. İlginç şekilde ülkede kadınların eğitim düzeyleri ile işsizlik oranları arasında da pozitif bir ilişki vardır. Lisans diplomasına sahip kadınlar arasında işsizlik oranı \%68'lere kadar tırmanmıştır (Inter-Agency Information and Analysis Unit (IAU), 2012). Bu durum, ülkede kadınlara uygun görülen işlerin nitelik gerektirmeyen ve daha çok beden gücüne yönelik (tarım işçiliği vb.) işler olduğu şeklinde yorumlanabilir. Görüldüğü üzere Irak; içinde bulunduğu savaş durumu, politik yapısı ve toplumsal koşullar sebebi ile kadınların iş hayatında ve sosyal yaşamda dünya geneline kıyasla çok daha fazla engelle mücadele ettiği bir bölgedir. Bu bahsedilenler araştırma evreninin Irak olarak seçilmesinde etkili olmuştur.

\section{ARAŞTIRMANIN AMACI VE YÖNTEMI}

$\mathrm{Bu}$ çalışmanın amacı, üniversitelerde görev yapan öğretim elemanlarının cam tavan engellerine ve güç mesafesine ilişkin algılarını tespit ederek, bu değişkenler arasında bir ilişki 
olup olmadığını ortaya koymaktır. Ayrıca akademisyenlerin bu değişkenlere ilişkin algılarının cinsiyete göre farklılık gösterip göstermediğinin tespit edilmesi de amaçlanmaktadır.

\section{II.1. Evren ve Örneklem}

Araştırmanın evrenini, bölgenin sosyopolitik yapısı sebebi ile isimlerinin paylaşılmasını istemeyen iki üniversitenin personeli oluşturmaktadır. Veri toplama sürecinde gerekli izinler alınarak toplam 536 adet anket dağıtılııștır. Bu anketlerden Üniversite 1'e gönderilen 341 anketin 300'ü cevaplanmış olup 3 tanesi geçersiz, 297'si tanesi geçerli kabul edilmiştir. Üniversite 2'ye ise 195 anket gönderilmiş ve bu anketlerden 129'u cevaplanmıs olup cevaplanan anketlerin tamamı geçerli kabul edilmiştir. Katılım oranı \%80 olarak gerçekleşmiştir.

\section{II.2. Araştırma Modeli ve Hipotezleri}

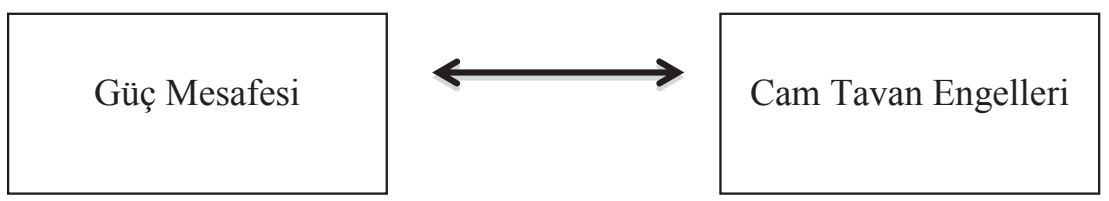

Şekil I: Hipotez 1

$\mathrm{H}_{1}$ : Akademisyenlerin güç mesafesi algılamaları ile cam tavan sendromuna yönelik algıları arasında ilişki vardır.

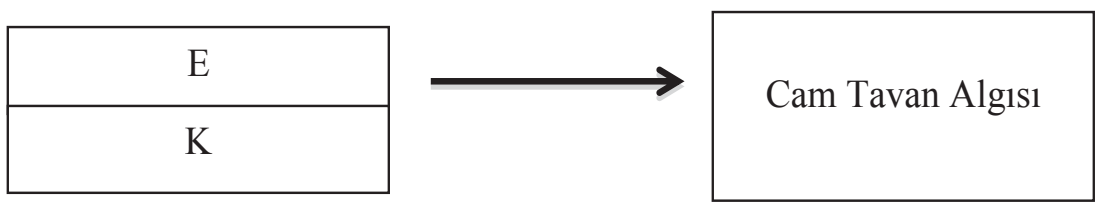

Şekil 2: Hipotez 2

$\mathrm{H}_{2}$ : Cinsiyete göre akademisyenlerin cam tavan algısı, farklılık göstermektedir.

\begin{tabular}{|c|}
\hline $\mathrm{E}$ \\
\hline $\mathrm{K}$ \\
\hline
\end{tabular}

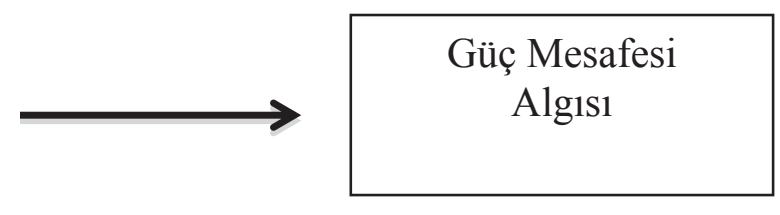

Şekil 3: Hipotez 3

$\mathrm{H}_{3}$ : Cinsiyete göre akademisyenlerin güç mesafesi algısı, farklılık göstermektedir. 


\section{II.3. Veri Toplama Yöntemi}

Bu çalı̧̧mada, Jahangirov (2012) tarafından yazılan "Kültürel Bir Değişken Olarak Güç Mesafesi ve Cam Tavan Engeli Arasındaki İlişkiler Üzerine Ampirik Bir Araştırma "isimli yüksek lisans tezinde yer alan anket formu tez yazarından izin alınarak kullanılmıştır. Anket üç bölümden oluşmaktadır. Birinci bölümde demografik sorular, ikinci bölümde güç mesafesi ile ilgili 10 ifade, üçüncü bölümde ise cam tavan sendromu ile ilgili 32 ifade yer almaktadır. Katılımcılardan ifadelere katılım derecelerini 5'li Likert ölçeğinde "1-kesinlikle katılmiyorum.2-kısmen katılmıyorum.3-ne katılıyorum ne katılmıyorum. 4-kısmen katılıyorum. 5-tamamen katılıyorum" olacak şekilde belirtmeleri istenmiştir.

Çalışma kapsamında anket formunun Türkçe'den Arapça'ya çevirisi yapılmış, bu süreçte uzman kişilerden görüş alınmıştır.

\section{II.4. Sınırlılıklar ve Varsayımlar}

Arap yarımadasındaki savaş durumu nedeniyle araştırma tek ülke ile sınırlı kalmış, yalnızca belirli bir bölgeden veri toplanabilmiştir. Bunun yanı sıra bölgede yaşanan maddi imkânsızlıklar nedeni ile sadece bölgedeki iki büyük üniversite çalışmaya dahil edilebilmiştir.

Bölgede daha önce bu konuda çalışmalar yapılmadı̆̆ından, akademisyenlerin anketleri cevaplandırırken, kurumlarını ve ülkelerini daha olumlu göstermek adına sorulara gerçek dışı yanıtlar vermeleri olasıdır. Katılımcıların anketleri doldururken düşüncelerini doğru yansıttıkları varsayılmıștır.

\section{II.5. Verilerin Analizi}

Güç mesafesi ve cam tavan engeli ifadelerinin bu kavramları ölçme konusunda ne kadar başarılı olduğunu tespit etmek için Cronbach Alpha güvenilirlik katsayıları hesaplanmıştır. Elde edilen güvenilirlik katsayıları şu şekildedir:

Tablo 1: Cronbach Alpha Güvenilirlik Katsayıları

\begin{tabular}{|l|l|l|l|}
\hline Değişkenler & No. of Items & Cronbach Alpha & Reliability \\
\hline Cam Tavan Sendromu & 32 & 0.98 & Yüksek Derecede Güvenilirlik \\
\hline Güç mesafesi & 10 & 0.99 & Yüksek Derecede Güvenilirlik \\
\hline
\end{tabular}

Alpha katsayısının değerlendirmesinde kullanılan değerlendirme ölçütleri aşağıdaki gibidir (Özdamar, 2002): 
Tablo 2: Cronbach Alpha Katsayıları Değerlendirme Ölçütleri

\begin{tabular}{|l|l|}
\hline Cronbach Alpha Katsayıları & Güvenilirlik Seviyesi \\
\hline $0.80-01.00$ & Yüksek derecede güvenilir \\
\hline $0.70-0.80$ & Güvenilir \\
\hline $0.65-0.70$ & Düşük seviyede güvenilir \\
\hline $0.60-0.65$ & Güvenilir değil \\
\hline
\end{tabular}

Tabloya bakıldığında cam tavan sendromu ve güç mesafesi algısını ölçmeye yönelik soruların güvenilirliğinin yüksek olduğu görülmektedir.

\section{BULGULAR}

\section{III.1. Katılımcıların Demografik Bilgileri}

Çalışmaya katılan 426 akademisyenin \%64,32'si erkek, \%35,68'i kadındır. Çalışmaya katılan kadın ve erkek akademiyenlerin yaş gruplarına göre dağılımları Şekil 4’te gösterilmiştir. Katılımcı yoğunluğunun en yüksek olduğu yaş aralığg 26-30 yaş aralığı olurken, en düşük olduğu yaş aralığı ise 41-45 yaş aralığıdır.

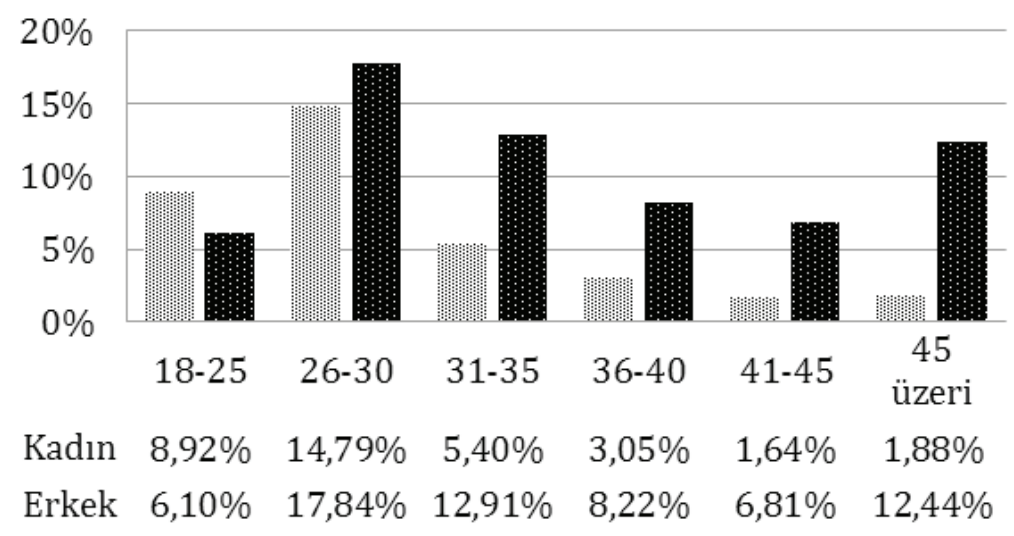

\section{II Kadın 田 Erkek}

Şekil 4: Katılımcıların Cinsiyete Göre Yaş Gruplarının Dağılımı

Çalışmaya katılan akademisyenlerin \%3,76'si profesör, \%13,15’i doçent, \%17,61'i yardımcı doçent, \%39,20’si öğretim görevlisi ve \%26,29’u araştırma görevlisi unvanına sahiptir. $\mathrm{Bu}$ akademisyenlerin \%21,37'si çalıştıkları üniversitede idari bir görev üstlenmektedir. Katılımcıların cinsiyetlerine ve unvanlarına göre idari görev dağılımı Şekil 5’te gösterilmiştir. 


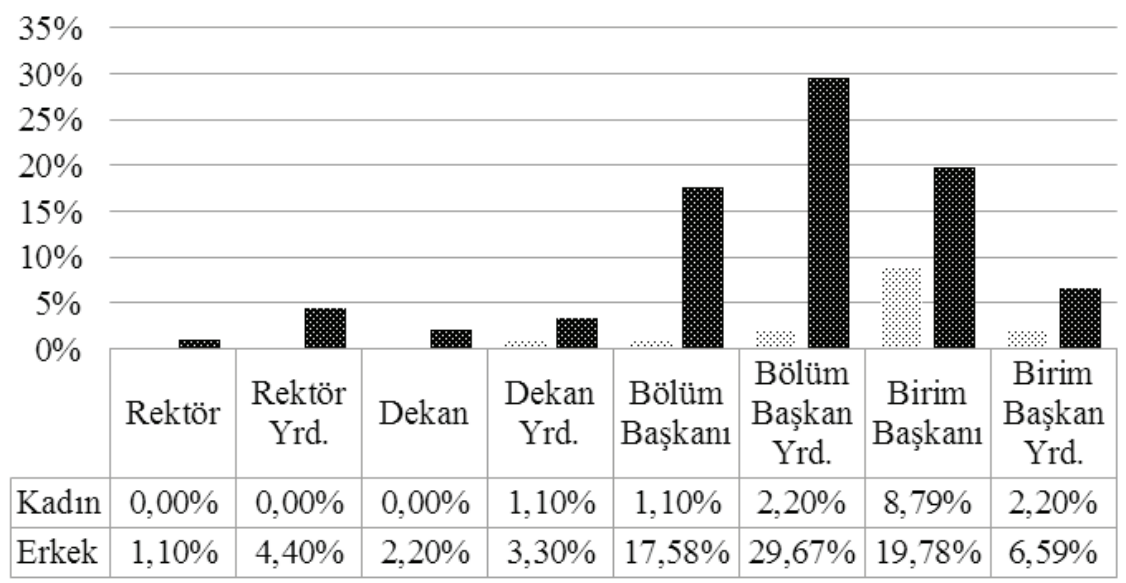

Kadın Erkek

Şekil 5: Katılımcıların Cinsiyetlerine ve Unvanlarına Göre İdari Görev Dağılımı

\section{III.2. Araştırmanın İstatistiki Sonuçları}

Tablo 3: Tanımlayıcı İstatistikler Sonuçları

\begin{tabular}{|l|l|l|l|}
\hline & Ortalama & Standart Sapma & N \\
\hline Güç Mesafesi & 3,60 &, 97 & 426 \\
\hline Cam Tavan & 3,04 & 1,01 & 426 \\
\hline
\end{tabular}

Tablo 3'te görüldüğü gibi, güç mesafesi ifadelerine verilen cevapların ortalaması 3,60, cam tavan sendromu ifadelerine verilen cevapların ortalaması 3.04'tır. Güç mesafesi soruları için standart sapma 97, cam tavan için ise standart sapma 1,01'dir.

Tablo 4: Pearson Korelasyon Sonuçları

\begin{tabular}{|l|l|l|l|}
\hline \multicolumn{2}{|c|}{} & Güç Mesafesi & Cam Tavan \\
\hline \multirow{4}{*}{ Güç Mesafesi } & PearsonCorrelation & 1 &, $973^{* *}$ \\
\cline { 2 - 4 } & Sig. (2-tailed) & &, 000 \\
\cline { 2 - 4 } & $\mathrm{N}$ & 426 & 426 \\
\hline${ }^{* *}$ korelasyon 0.01 düzeyinde anlamlı (2-tailed). & \multicolumn{2}{|l}{} \\
\hline
\end{tabular}

Tablo 4'te görüldüğü gibi, sig değeri 0,05’ten küçüktür. Bu sonuca göre güç mesafesi ve cam tavan engelleri algısı arasında anlamlı bir ilişki olduğu görülmektedir. Bu ilişki pozitif yönlü ve güçlü bir ilişkidir. Araştırma hipotezlerinden " $\mathrm{H}_{1:}$ Akademisyenlerin güç mesafesi 
algılamaları ile cam tavan sendromuna yönelik algıları arasında ilişki vardır.” hipotezi kabul edilmiştir.

Tablo 5: Cam Tavan’a İlişkin Grup İstatistikleri Sonuçları

\begin{tabular}{|l|l|l|l|l|}
\hline & Cinsiyet & N & Ortalama & Standart Sapma \\
\hline Cam Tavan & Erkek & 274 & 3,04 & 1,01 \\
\hline & Kadın & 152 & 3,04 & 1,02 \\
\hline
\end{tabular}

Tablo 5’te görüldüğü gibi, cam tavan ile ilgili ifadelere kadın ve erkek katılımcıların verdikleri cevapların ortalaması 3,04'dür ve standart sapma erkeklerde 1,01 kadınlarda ise 1,02 'dir.

Tablo 6: Cam Tavana ilişkin Independent Samples Test (T.test) Sonuçları

\begin{tabular}{|c|c|c|c|c|c|c|c|c|c|c|}
\hline & \multicolumn{2}{|c|}{$\begin{array}{l}\text { Varyansların } \\
\text { Eşitliği İçin } \\
\text { Levene Testi }\end{array}$} & \multicolumn{7}{|c|}{ Ortalamaların Eşitliği İçin T-Testi } \\
\hline & & \multirow[t]{2}{*}{$\mathrm{F}$} & \multirow[t]{2}{*}{ Sig. } & \multirow[t]{2}{*}{$\mathrm{T}$} & \multirow[t]{2}{*}{ df } & \multirow{2}{*}{$\begin{array}{l}\text { Sig. } \\
\text { (2-tailed) }\end{array}$} & \multirow{2}{*}{$\begin{array}{l}\text { Fark } \\
\text { Ortalaması }\end{array}$} & \multirow{2}{*}{$\begin{array}{l}\text { Std. Hata } \\
\text { Fark1 }\end{array}$} & \multicolumn{2}{|c|}{$\begin{array}{l}\text { Fark \%95 Güven } \\
\text { Aralığ }\end{array}$} \\
\hline & & & & & & & & & alt & üst \\
\hline \multirow[t]{2}{*}{$\begin{array}{l}\text { Cam } \\
\text { Tavan } \\
\end{array}$} & $\begin{array}{l}\text { Eşit Varyanslar } \\
\text { Varsayıllır } \\
\end{array}$ & ,258 & ,612 &, 010 & 424 & 992 &, 00105 &, 10326 &,- 20192 & ,20402 \\
\hline & $\begin{array}{l}\text { Eşit Varyanslar } \\
\text { Varsayılmaz }\end{array}$ & & &, 010 & & ,992 & ,00105 &, 10365 &,- 20291 & ,20501 \\
\hline
\end{tabular}

Tablo 6’da görüldüğü gibi, sig değeri (0,992) 0,05’ten büyük olduğu için kadın ve erkeklerin cam tavana ilişkin ifadelere verdikleri cevapların ortalamaları arasında istatistiksel olarak anlamlı bir fark yoktur. Bu sonuç ışı̆̆ında araştırmanın hipotezlerinden olan " $\mathrm{H}_{2 \text { : }}$ Cinsiyete göre akademisyenlerin cam tavan algısı, farklılık göstermektedir.” reddedilmiștir.

Tablo7: Güç Mesafesine İlişkin Grup İstatistikleri Sonuçları

\begin{tabular}{|l|l|l|l|l|}
\hline & Cinsiyet & N & Ortalama & Standart Sapma \\
\hline Güç Mesafesi & Erkek & 274 & 3,63 &, 98 \\
\hline & Kadın & 152 & 3,57 &, 95 \\
\hline
\end{tabular}

Tablo 7’de görüldügü gibi, güç mesafesi sorularına kadın ve erkek katılımcıların verdikleri cevapların ortalaması erkeklerde 3,63ve kadınlarda 3,57'dir. Standart sapma erkekler için 98, kadınlar için ise 95'dir. 
Tablo 8: Güç Mesafesine ilişkin Independent Samples Test (T.test) Sonuçları

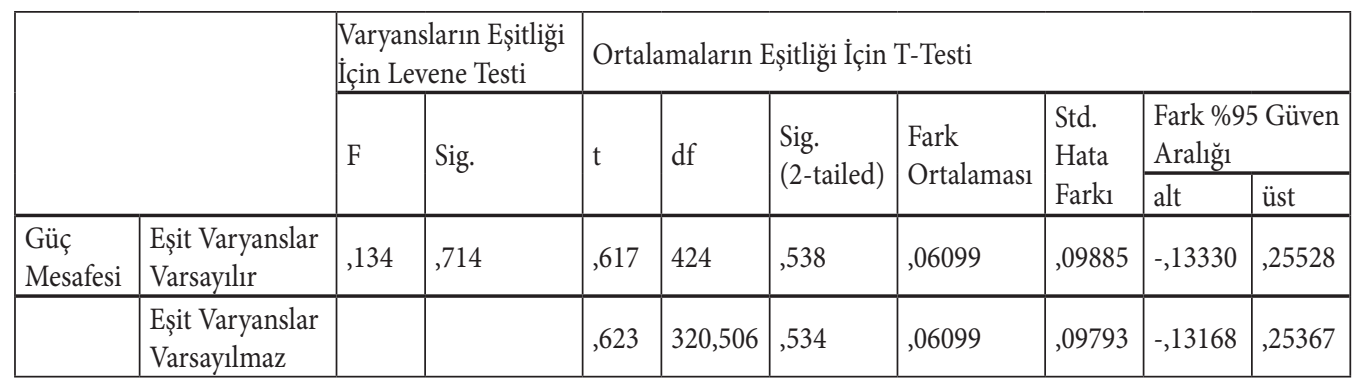

Tablo 8'de görüldüğü gibi, sig değeri $(0,538)$ 0,05'ten büyük olduğu için kadın ve erkeklerin güç mesafesine ilişkin ifadelere verdikleri cevapların ortalamaları arasında istatistiksel olarakanlamlı bir fark yoktur. Bu sonuç ışığında araştırmanın hipotezlerinden olan “ H3: Cinsiyete göre akademisyenlerin güç mesafesi algısı, farklılık göstermektedir” reddedilmiştir.

\section{SONUÇ VE ÖNERILER}

Genel sonuç olarak, literatüre paralel şekilde cam tavan engelleri ve güç mesafesi arasında pozitif yönlü ve güçlü bir ilişki olduğu görülmektedir. Bu ilişki, güç mesafesinin artmasıyla cam tavan engellerin artması, güç mesafesinin azalmasıyla da cam tavan engellerin varlığının hissedilebilir derecede azalması veya ortadan kalkması şeklinde bir sonuç doğurmaktadır. Cam tavan engelleri ve güç mesafesine yönelik algıda ise cinsiyete dayalı bir fark gözükmemektedir.

Eğitim seviyesinin yükselmesi, mesleki ayrımın yapılmaması ve kanun, örf, adet gibi bağlayıcı normların etkisiyle cam tavan engelleri ve güç mesafesinin tamamen ortadan kaldıralabileceği ya da doğurduğu olumsuz sonuçların en az seviyeye indirilebileceği söylenebilir. Bu bağlayıcı normlara bir örnek olarak İngiltere'de FTSE100 endeksinde yer alan işletmelerin başlatmış olduğu kampanya gösterilebilir. 2025 yılına kadar, endekste yer alan 100 firmadan minimum 25 tanesinin CEO / CFO’larının kadın çalışan olmasına yönelik düzenlenen kampanya kamuoyunda da ilgi ve destek görmüştür. Bu girişimle ilk yılın sonunda FTSE100 endeksinde yer alan şirketlerdeki kadın CEO sayısı 5'den 7’ye yükselmiş, kadın CFO sayısı ise 12 olmuştur (Hürriyet, 2016).

Kadınların üst yönetim pozisyonlarına yükselmelerinin önündeki engellerden biri de zihinsel kodlardır. KPMG Türkiye ve Yönetim Kurulunda Kadın Derneği işbirliği ile hazırlanan ve 2017 yılında yayınlanan rapora göre kadınların yönetici olmaları yönündeki engeller araştırıldığında ilk iki sırada "kadının büyük bir şartlanmayla baştan yöneticiliğe düşünülmemesi” ve "kadının kendi şartlanmışlığı ile zaten yöneticiliği hedefine koymaması” gelmektedir (KPMG, 2017). Bu sonuç, cam tavan sendromuna neden olan toplumsal faktörlere örnek teşkil etmekte ve toplumda cinsiyete dayalı zihniyet kalıplar değişmedikçe işletmelerde 
kadınların yönetim kademelerine yükselmelerinin önünün açılamayacağına işaret etmektedir. Dünya Ekonomik Forumu Cinsiyet Eşitliği Endeksine göre 2016 yılı itibari ile cinsiyet eşitliği bakımından 144 ülke içerisinde 130. sırada yer alan ülkemiz için bu durum daha da kritik bir öneme sahiptir (World Economic Forum, 2017). Türkiye'deki kadın iş gücü değerlendirilmeyen büyük bir potansiyel teşkil etmektedir. Ülkemiz kadınların iş gücüne katılımında OECD ülkeleri arasında en düşük seviyededir. OECD ülkeleri için ortalama \%63 seviyesindeyken, Türkiye'de bu oran sadece \%34'tür. Ülkemizin kadınların iş gücüne kat1lımında OECD ülkeleri seviyesine ulaşması senaryosunda, 2025 yılı için Türkiye Gayrisafi Yurtiçi Hasılasında yaklaşık \%20'lik bir artış potansiyeli öngörülmektedir (Devillard-Hoellinger, vd., 2017: 2).

İşletmelerde kadın temsil oranının artması ve kadınların üst yönetim pozisyonlarına yükselmesinin, çeşitliliği arttırarak işletme performansını arttırması ve örgüt kültürünü geliştirmesi olasıdır. McKinsey firması tarafından 2010 yılında yayınlanan global raporda, kadınların üst yönetim takımlarında yer almasının şirketlerin finansal performansını olumlu etkilediğini ortaya konmuştur. Dünya genelinde 279 firma üzerinde yapılan araştırmanın sonuçlarına gore üst yönetim takımında en az 1 kadın bulunan firmaların ortalama öz sermaye karlılığ $\% 22$ seviyesindeyken, üst yönetim takımında kadın çalışan bulunmayan firmalarda bu oran olarak \%15 gerçekleşmiştir (Desvaux, Devillard ve Sancier-Sultan, 2010: 7). $\mathrm{Bu}$ ve benzeri çalışmalar, toplumsal yapı sebebi ile kadınların işgücüne katılımın düşük olduğu Irak vb. ülkelerde, kadın çalışanların kendi potansiyellerine dair farkındalıklarının artmasına ve kadın yöneticilere yönelik önyargıların yıkılmasına hizmet ederek cam tavan engellerinin azalmasına yardımcı olabilecektir.

\section{Yararlanılan Kaynaklar}

Deloitte. (2015). Women in the boardroom: A global perspective, tarihinde https://www2. deloitte.com/global/en/pages/risk/articles/women-in-the-boardroom.html (Erişim tarihi: 01.05.2017).

Desvaux, G., Devillard, S. ve Sancier-Sultan, S. (2010). Women Matter 2010: Women at the top of corporations: Making it happen. McKinsey\&Company, http://www.mckinsey. com/business-functions/organization/our-insights/women-at-the-top-of-corporationsmaking-it-happen (Erişim Tarihi 21.06.2017).

Devillard-Hoellinger, S., Gökler,P., Korkmaz, B. ve Tanrıkulu, Ö. (2017). Women Matter Turkey 2016: Turkey's potential for the future: Women in business. McKinsey\&Company, http:// www.mckinsey.com.tr/arastirma-ve-yayinlarimiz/WomenMatterTurkey2016Report.pdf (Erişim Tarihi 21.06.2017).

Hofstede, G. (2003). Culture's consequences: Comparing values, behaviors, institutions and organizations across nations. Sage publications. 
Hofstede, G., Hofstede, G. J. ve Minkov, M. (2010). Cultures and organizations: Software of the mind (Rev. 3rd ed.). New York: McGraw-Hill.

Hymowitz, C. ve Schellhardt, T. D. (1986). The glass ceiling: Why women can't seem to break the invisible barrier that blocks them from the top jobs. The Wall Street Journal, 24(1), 15731592.

Inter-Agency Information and Analysis Unit (IAU). (2012). Women in Iraq fact sheet. http:// nina-iraq.com/wp-content/uploads/2014/03/Women-In-Iraq-Fact-sheet-English.pdf. (Erişim tarihi: 21.06.2017).

Jahangirov, N. (2012). Kültürel bir değişken olarak güç mesafesi ve cam tavan engeli arasındaki ilişkiler üzerine ampirik bir araştırma. Yayımlanmamış Yüksek Lisans Tezi, Gazi Üniversitesi Eğitim Bilimler Enstitüsü, Ankara.

Kadın Yöneticiler Artıyor. (2016, 11 Kasım). http://www.hurriyet.com.tr/kadin-yoneticilerartiyor-40275166 (Erişim tarihi: 15.06.2017).

Kadınlar Kilidi Kırıyor. (2017, 25 Mayıs). https://home.kpmg.com/tr/tr/home/media/pressreleases/2017/05/kadinlar-kilidi-kiriyor.html Erişim tarihi: 15.06.2017).

Mizrahi, R., ve Aracı, H. (2010). Kadın yöneticiler ve cam tavan sendromu üzerine bir araştırma. Organizasyon ve Yönetim Bilimleri Dergisi, 2(1).149-156.

Özdamar, K. (2002). Paket Programlar ile İstatistiksel Veri Analizi. Eskişehir: Kaan Kitapevi.

The World Bank. (2017). Labor force participation rate, female (\% of female population ages 15+) (modeled ILO estimate), http://data.worldbank.org/indicator/SL.TLF.CACT. FE.ZS? end=2016\&start=2016\&view=map\&year=2016 (Erişim tarihi: 21.06.2017).

Turan, S., Durceylan, B. \& Şişman, M. (2005). Üniversite yöneticilerinin benimsedikleri idari ve kültürel değerler. Manas Üniversitesi Sosyal Bilimler Dergisi, 7(13), 181-202.

Women in business: New perspectives on risk and reward.(2017). Grant Thornton International Ltd., s.5. https://www.grantthornton.com.au/insights/reports/women-in-business-newperspectives-on-risk-and-reward/ (Erişim tarihi: 21.06.2017).

World Economic Forum. (2017). The Global Gender Gap Index, http://reports.weforum.org/ global-gender-gap-report-2016/rankings/ (Erişim tarihi: 20.06.2017). 


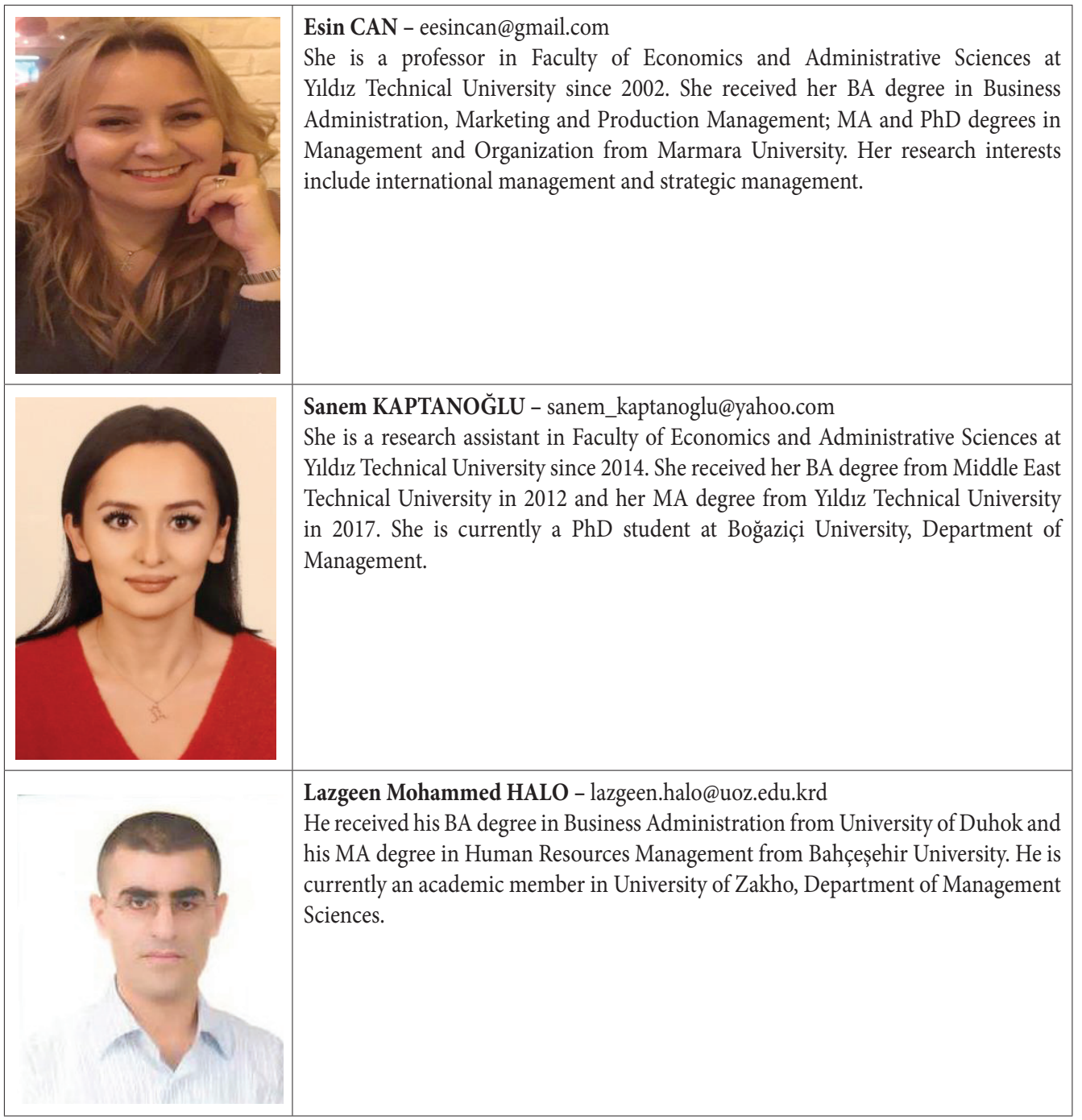

